First Peoples Child \& Family Review

A Journal on Innovation and Best Practices in Aboriginal Child Welfare Administration,

Research, Policy \& Practice

\title{
Intercultural Communications and Conductive Hearing Loss
}

\section{Damien Howard}

Volume 3, Number 4, 2007

URI: https://id.erudit.org/iderudit/1069379ar

DOI: https://doi.org/10.7202/1069379ar

See table of contents

Publisher(s)

First Nations Child and Family Caring Society of Canada

ISSN

1708-489X (print)

2293-6610 (digital)

Explore this journal

Cite this article

Howard, D. (2007). Intercultural Communications and Conductive Hearing Loss. First Peoples Child \& Family Review, 3(4), 96-105.

https://doi.org/10.7202/1069379ar

\section{Article abstract}

Widespread conductive hearing loss among Aboriginal peoples in first world nations has a significant, although largely invisible impact on intercultural communication. Poor acoustics and cultural differences in communication styles compound the effect of widespread hearing loss among Aboriginal peoples. This article considers Australian research that has investigated how conductive hearing loss can impact on intercultural communication in schools and in the criminal justice system, as well as communication processes within Aboriginal families. An understanding of these issues can facilitate the development of innovative interventions that can help address Aboriginal disadvantage, especially within mainstream institutions.
This document is protected by copyright law. Use of the services of Erudit (including reproduction) is subject to its terms and conditions, which can be viewed online.

https://apropos.erudit.org/en/users/policy-on-use/ 


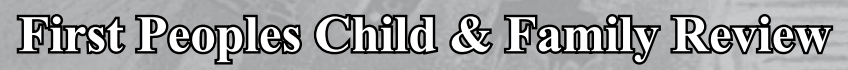

A Journal on Innovation and Best Practices in Aboriginal Child Welfare Administration, Research, Policy \& Practice

Volume 3, Number 4, 2007, pp. 96-105

\title{
Intercultural Communications and Conductive Hearing Loss
}

\author{
Damien Howard
}

Dr. Damien Howard is an Australian psychologist and educator with a research interest in the social outcomes of middle ear disease, especially among Aboriginal people. He lives in the Northern Territory of Australia where 30 per cent of the population is Aboriginal, many of whom live in remote communities in extreme poverty and where middle ear disease is endemic. He has worked in these communities as well as more urban contexts as a teacher, psychologist, cross-cultural consultant and researcher. A number of research reports and resources developed by him are available at www.eartroubles.com.

\section{Introduction}

Cultural and linguistic differences are critical factors to consider in intercultural communication. However, the widespread hearing loss that is known to exist in Aboriginal communities can also have a significant and adverse impact on communication, especially intercultural communication. Children who grow up in poverty, who live in crowded housing, and who experience poor nutrition and inadequate health care, are prone to repeated severe episodes of middle ear disease (otitis media). These episodes can often cause conductive hearing loss (Bowd, 2005; Couzos, Metcalf \& Murray, 2001).

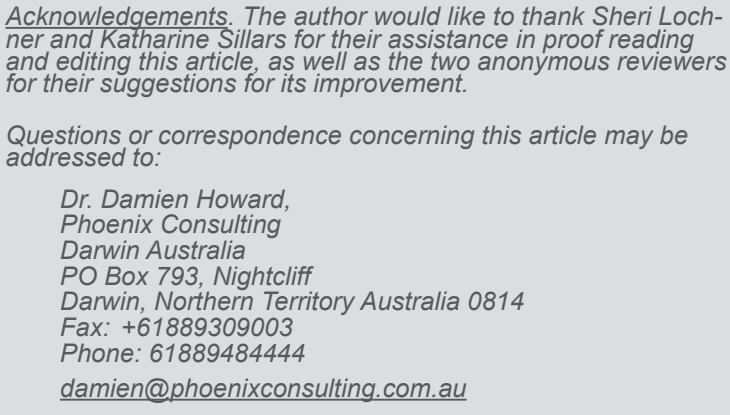

\begin{abstract}
Widespread conductive hearing loss among Aboriginal peoples in first world nations has a significant, although largely invisible impact on intercultural communication. Poor acoustics and cultural differences in communication styles compound the effect of widespread hearing loss among Aboriginal peoples. This article considers Australian research that has investigated how conductive hearing loss can impact on intercultural communication in schools and in the criminal justice system, as well as communication processes within Aboriginal families. An understanding of these issues can facilitate the development of innovative interventions that can help address Aboriginal disadvantage, especially within mainstream institutions.
\end{abstract}

In Canada, otitis media is endemic among Inuit, First Nation and Métis children in northern Canada, with prevalence rates as high as 40 times that found in the urban south. Conductive hearing loss among children may affect as many as two-thirds of Aboriginal children in northern Canada (Bowd, 2005). In Australia, as many as 80 per cent of the Aboriginal children in remote communities have some degree of conductive hearing loss (Couzos, Metcalf \& Murray, 2001).

\section{Different types of hearing loss}

When thinking about hearing loss people generally think of those who are 'deaf', that is those who have severe to profound levels of permanent hearing loss. However, there are a far greater number of people who have less severe and sometimes fluctuating levels of often unidentified hearing loss. This is especially true amongst children.

People who are pre-lingually deaf (that is, profoundly deaf before developing oral language) are noticeable because of their manner of speech and/or because they rely on sign language and lip reading for communication. In contrast, people with slight, mild and moderate hearing 
loss are less noticeable. They use spoken language as their primary means of communication and their ability to listen and hear may be adversely affected in only some situations. Nevertheless, mild to moderate levels of hearing loss can still have significant social, educational and occupational implications.

\section{Conductive hearing loss, otitis media and 'listening problems'}

'Conductive hearing loss' is hearing loss caused by problems that affect the transmission of sound impulses before they enter the inner ear. The term refers to the way sound is transmitted by mechanical conduction through the vibration of the eardrum (tympanic membrane), along the small bones in the middle ear, and then through the pressurised air in the middle ear. Conductive hearing loss among children is most often the result of infection in the middle ear - otitis media.

The infection causes a build up of fluid in the middle ear. The pressure exerted by this fluid can build up to the point where the eardrum bursts, or perforates. The fluid build up and eardrum perforations inhibit the transmission or conduction of sound through the ear. In most developed communities otitis media is a common but short-term childhood illness that is resolved by the time children begin school (Bluestone, 1998). However, in communities where children grow up in overcrowded housing, have poor nutrition and limited access to health care, middle ear disease is more prevalent and more severe (Couzos, Metcalf \& Murray, 2001). Children from these communities often experience mild to moderate fluctuating conductive hearing loss during their school years.

Aboriginal Australians, Canadians and Americans (WHO, 1996), and Pacific Island and Maori children in New Zealand (Greville, 2001) have a known higher prevalence of middle ear disease and associated conductive hearing loss than other population groups in those countries. It has been estimated that Aboriginal children in Australia experience middle ear disease and related hearing loss throughout their childhood for an average of two and a half years, while the average for children in the mainstream Australian community is just three months (Couzos, Metcalf \& Murray, 2001).

Childhood middle ear disease also contributes to a secondary condition - problems with the processing of auditory information. The persistent partial sensory deprivation that results from the conductive hearing loss associated with middle ear disease can inhibit the development of the neurological abilities needed to process sounds (Hogan \& Moore, 2003). This can lead to an ongoing auditory processing problem, which is sometimes referred to as a central auditory processing disorder. While about 10 per cent of people in the general community are affected by auditory processing problems, one Australian study found that 38 per cent of a group of Aboriginal secondary students showed signs of auditory processing problems (Yonovitz \& Yonovitz, 2000).

'Listening problems' are especially evident in noisy situations and are related to a combination of conductive hearing loss and auditory processing problems, both of which are caused by past or current middle ear disease. For the sake of descriptive simplicity in this article, this combination of problems is termed 'conductive hearing loss' or 'hearing loss'.

Conductive hearing loss is widespread among Aboriginal adults as well as among Aboriginal children. While intermittent conductive hearing loss is most common among children, many Aboriginal adults have some degree of ongoing conductive hearing loss as a result of significant uncorrected damage to the middle ear caused by repeated infections during childhood. In Canada it is estimated that 44 percent of Inuit, and 39 percent of First Nations adults living in reserves or settlements have hearing loss (Bowd, 2005). For remote Australian communities, studies have found 50 percent of Indigenous tertiary students (Lay, 1990) and 60 per cent of a group of Aboriginal workers have some degree of hearing loss (Howard, 2007a).

In developed Western countries with Aboriginal minorities (Canada, Australia, New Zealand) research in the area has mostly been restricted to studies of the health aspects of ear disease among Aboriginal peoples (Bowd, 2005; Couzos, Metcalf \& Murray, 2001). However, in Australia there is also a small body of research on the effect of conductive hearing loss on educational and social outcomes of ear disease among Aboriginal people. This is described in the following sections.

\section{Intercultural Communications in Classrooms}

\author{
'All of the kids with that ear problem, they're \\ fighting or bullying the other kids [at school].' \\ (Australian Aboriginal Health Worker)
}

In intercultural classroom settings ${ }^{1}$ Australian Aboriginal students with conductive hearing loss have been found to participate less than other students in the highly verbal Australian teaching processes. Studies have showed that they contribute little to class discussions and are less likely to answer questions. Often they are also the students who are most disruptive in class (Howard, 2004); and they tend to be less academically successful at school (Yonovitz \& Yonovitz, 2000). In part, this is because persistent conductive hearing loss makes it more difficult for the affected Aboriginal children to acquire language skills, especially when learning English as a second or 
third language (Jacobs, 1988; Yonovitz \& Yonovitz, 2000; Howard, 2007a). However, their classroom and language based learning difficulties are also related to aspects of the classroom environment.

Classroom based research in Australia points to a number of mediating factors that influence the extent to which adverse communication and social outcomes result from conductive hearing loss among Aboriginal children (Howard, 2004; Howard, 2006a). These factors are:

- The cultural context of the classroom;

- The teachers' perceptions of, and responses to the behaviour of Aboriginal children with conductive hearing loss; and

- The levels of background noise in schools.

\section{Classroom cultural context and hearing loss}

In Australia, most Aboriginal children are taught in standard Australian English by a non-Aboriginal teacher. In this setting certain factors appear to compound the difficulties associated with hearing loss for Aboriginal children (Howard, 2006a).

- They face culturally unfamiliar and highly verbal teaching styles that require students to learn from listening to teachers and peers in an artificial classroom environment;

- Their classrooms are often noisy and seldom have adequate acoustics for Aboriginal children with hearing loss.

The standard classroom approach to teaching and learning differs markedly from the traditional styles of education found in many Aboriginal cultures, where learning occurs in small groups or 'one-to-one' and in real life contexts (Harris, 1980; Erickson \& Mohatt, 1981). These more informal styles of education have many advantages for children with mild to moderate hearing loss.

- Firstly, real life contexts provide children with multi-sensory learning cues - they can observe tasks as they are demonstrated, so they do not have to rely on mainly spoken explanations;

- Secondly, the levels of background noise in one-toone or small group instruction in real life settings are often lower than they are in classrooms.

Moreover, it is easier for children to understand someone who is known, speaking a familiar language, and who is able to talk about topics within the context of a familiar cultural framework. These 'familiar' supports for communication and learning become critical when conductive hearing loss reduces the information that is otherwise available from listening.
The evidence from Australia suggests that if Aboriginal students are taught in the language with which they are most familiar, in a wholly Aboriginal class group, by a teacher from the same cultural group, the risk of the adverse communication and social outcomes for the children with conductive hearing loss appears to be minimized (Lowell, 1994; Massie, 1999; Howard 2004). When teachers are from their own culture, children can learn within a framework of cultural and linguistic 'familiarity' that makes it easier for them to understand what is said. 'Familiarity' with the person, language and culture helps children to 'fill in the gaps' that result from diminished auditory input. Without such non-auditory supports and aids to understanding, Aboriginal people with hearing loss (adults as well as children) can find speech difficult to comprehend. When they do this can in turn lead to fear of being 'shamed' - because they have not understood - and the resulting anxiety can compound the difficulties with understanding. The problem becomes a cyclical and negatively reinforcing one, and one that, for Aboriginal children with conductive hearing loss, can limit their ability to learn and to develop essential understandings of culturally unfamiliar 'world views'.

\section{Conductive Hearing Loss and 'Worldviews'}

A shared 'worldview' is important for successful inter-cultural communication. Shared 'worldviews' develop as the result of a series of successful crosscultural negotiations over time (Lowell et al., 2004). However, people with conductive hearing loss and who come from minority cultures are less likely to be able to successfully participate in the interchanges and negotiations that are needed to arrive at a shared 'worldview' (Howard, 2006b).

Firstly, when people with conductive hearing loss do engage in intercultural communication, they are often unable to do so as successfully as those who can hear well. They may misunderstand what is said. They are often slower to learn concepts. They may distract a group with 'off topic' interjections, or they may just maintain a perplexed silence (Howard, 2006a). Secondly, Aboriginal people with conductive hearing loss often seek to cope with their communication difficulties by avoiding or minimizing their involvement in intercultural communication. In the case of Aboriginal children with conductive hearing loss in Australia, they are absent from school more often than others (NACCHO, 2003). When they are at school they are more likely to try to avoid engagement with their teachers and involvement in many classroom activities (Howard, 1994, 2004).

Many Aboriginal adults with hearing loss employ the same tactics - absence or avoidance. 
"I try to have little to do with white people" (Aboriginal Health Worker with hearing loss).

By avoiding or minimizing their involvement in intercultural communication, Aboriginal people with hearing loss are dealing with the anxiety they may otherwise experience during intercultural communication, where successful communication depends on levels of auditory/verbal skill they do not have. However, if they are familiar with the people and social processes involved, this can help to minimize their anxiety, notwithstanding any hearing loss. Conversely, communication with unfamiliar people in the context of unfamiliar social processes compounds the communication difficulties that result from hearing loss. For example, school children with hearing loss often have more difficulty when dealing with a temporary teacher (an unfamiliar person) and exhibit more significant behaviour problems when they are participating in school excursions (involves unfamiliar social process).

Over time, their adverse experiences and negative response patterns have a cumulative result. To begin with, they experience basic communication difficulties. They have difficulty hearing-what-is-said, because of their hearing loss. This, in turn, can lead to difficulty with understanding-what-is-heard, because they have not acquired the familiarity with Western 'worldviews' that would help them to understand-what-is-said. The problem compounds first in childhood and then into adulthood; many people with conductive hearing loss seek to avoid or minimize the risks of intercultural communication - anxiety, communicative failure and 'shame'. As a result, those with conductive hearing loss develop less familiarity with Western ways of doing things than do other members of their group.

The effects of this disengagement can be seen in the comment from a teacher when told which of the Aboriginal children in her class had been identified as having conductive hearing loss. She said that she had thought her difficulties in communicating with and relating to these students had arisen because they were "more Aboriginal" than other students. This comment is indicative of the way in which hearing loss can obstruct the development of shared 'worldviews'. It also serves to show how a focus on 'cultural differences,' as an explanation for intercultural communication difficulties, can obscure recognition of the contribution that conductive hearing loss often makes to these difficulties.

\section{Relationships with Teachers}

The way teachers view children's classroom behaviours (which may be related to a hearing loss) and the way teachers respond to these behaviours are mediating factors in the disadvantage experienced by Aboriginal children with conductive hearing loss.
For Aboriginal students, their relationships with their teachers are a key factor in their success at school (Malin, 1990). Some students with conductive hearing loss actively avoid engagement with teachers, misunderstand what is said, fail to complete work, are disruptive in class and tease their peers. The teachers often see these types of classroom behaviour as a function of poor motivation, limited ability or overt defiance. In one study, the Aboriginal students that non-Aboriginal teachers said they had most difficulty relating to were the ones who were found to have conductive hearing loss (Howard, 2006a). However, when teachers know which children have conductive hearing loss and understand how certain classroom responses are shaped by conductive hearing loss, as well as how to communicate better with these students, then the students' engagement in learning as well as their relationships with their teachers improves. At the same time, the amount of antisocial behavior decreases (Howard, 2006a; Hookey, 2007).

\section{Background noise}

Background noise can significantly increase communication difficulties for people with conductive hearing loss. Although people with mild to moderate hearing loss may cope when listening in a quiet environment, they experience difficulties as the background noise level rises (Whitlock \& Dodd, 2003; Finitzo-Hieber \& Tillman, 1978). School environments are often noisy because of the activity and talk among groups of children congregated in confined and often acoustically poor classrooms (Wilson et al., 2002). In these situations, Aboriginal children with conductive hearing loss experience learning difficulties and display lower levels of achievement (Yonovitz \& Yonovitz, 2000; Howard, 2004) as well as poor social and emotional outcomes and higher levels of antisocial behaviour (Zubrick et al, 2004; Howard, 2004).

Thus, the evidence from research in schools, from an Australian perspective, serves to confirm that the consequences of schooling for Aboriginal children with conductive hearing loss are significantly mediated by cultural context, non-Aboriginal teachers' perceptions of and responses to student behaviour, and noise levels in classrooms. These factors interact synergistically with conductive hearing loss to determine the level of disadvantage that can be associated with conductive hearing loss. The same factors also influence outcomes when Aboriginal people become involved with the criminal justice system.

\section{The criminal justice system}

In Australia and New Zealand, there is evidence that a higher proportion of Aboriginal prison inmates have 
some degree of hearing loss when compared with the general incidence of conductive hearing loss in the total Aboriginal population (Bowers, 1986; Murray \& La Page, 2004). This suggests that:

\section{Involvement in the criminal justice system may be the end product of a cumulative link, whereby hearing-related social problems contribute to low educational standards, unemployment, alcohol and substance abuse, these being the more obvious antecedents of contact with the criminal justice system (Howard et al., 1991, p 9).}

And here, as in schools, difficulties with intercultural communication processes, the perceptions and responses of non-Aboriginal staff and background noise levels, in combination with conductive hearing loss, can and do lead to significant communication problems.

Linguistic and cultural differences are frequently presumed to be the reason why an Aboriginal witness may misinterpret a question, give an inexplicable answer, remain silent in response to a question or ask for a question to be repeated. The potential contribution of conductive hearing loss to a break down of communication is generally not considered. However, it is probable that the distinctive demeanor of many Australian Aboriginal people in court is related to their hearing loss. Where this is the case there is a very real danger that the court-room demeanour of Aboriginal people (not answering questions, avoiding eye contact, turning away from people who try to communicate with them) may be being interpreted as indicative of guilt, defiance or contempt (Howard, 2006c).

Court processes are largely an artifact of 'Western' culture. The social processes are structured and highly formal and the language used is often obscure, even to native English speakers. Yet Aboriginal people can be disadvantaged if they do not participate fully in court processes that involve archaic examples of 'Western' social etiquette and a specialized English vocabulary. An anthropologist made the following comment after observing Aboriginal defendants in court proceedings:

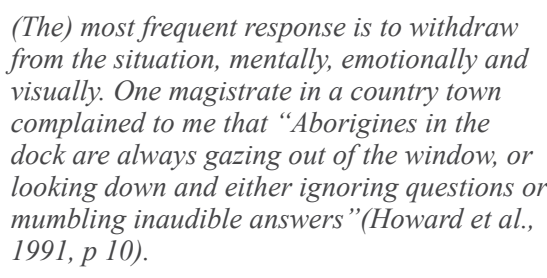

Also, as is the case between a student and his/her teacher, conductive hearing loss can jeopardise the building of rapport and quality communication between a client and his/her legal counsel. Yet a good relationship between them is critical to effective representation within the criminal justice system.
One Aboriginal man with hearing loss related that, years earlier, feeling confused and embarrassed about his hearing-related communication difficulties, he pleaded guilty to a charge of which he believed he was innocent. He thought it would be easier to plead guilty than to try to explain (through his lawyer) his innocence in court. He subsequently spent six months in prison (Howard et al., 1991, $p$ 11).

The following anecdotes are indicative of ways in which communication elsewhere in the criminal justice system can also be adversely affected by conductive hearing loss, with perverse consequences.

A defendant with hearing loss was crash tackled
when being transported from court when he did
not obey a verbal order to stop, that he did not
hear.
After sentencing, a defendant with hearing loss
was placed in an unfamiliar room to be told
what his sentence meant. His usual lawyer was
not available because of other commitments, so
another unfamiliar lawyer tried to explain the
sentence. However, the man became wild and
'trashed' the room when the new lawyer tried
to explain the court outcome. He only calmed
down when familiar staff from the detention
centre arrived.
A long term feud developed between a hearing
impaired prisoner and another prisoner after
a hearing related misunderstanding during a
game of cricket in prison (Howard, 2006c, $p$ 9).

In the criminal justice system, background noise also plays an important role in communication problems for people with conductive hearing loss. A group of prison staff linked the places and times when it was noisiest with the incidence of most arguments between inmates. They also noted that the number of fights reduced when the public phones used by inmates were enclosed to better sound proof them, because people using the phones experienced less frustration as a result of noise intrusion (Personal communication, 2006).

There is also evidence that hearing loss can inhibit not only intercultural communication but also communication between Aboriginal people.

\section{Family life}

Research into the influence of conductive hearing loss within families indicates that conductive hearing loss can have an impact on communication between people from the same cultural background. One small qualitative study (Howard \& Hampton, 2006) supports the view that conductive hearing loss can have a negative effect on family life. 


\section{First Peoples Child \& Family Review, Volume 3, Number 4, 2007}

Half the kids get floggings [beatings] because they [the family] think they're [the children] ignoring them. I see parents giving kids with hearing loss a flogging when they [the children] have not understood - I see that all the time, everywhere.'

They are cheeky...you see a kid [who has middle ear disease] throwing rocks at Mum and swearing and demanding something, and usually most times they will give it to them to shut them up (Aboriginal Health Workers -Howard \& Hampton, 2006, p2).

There is also evidence of the adverse effects that a child with conductive hearing loss can have on other family members.

\begin{abstract}
I felt depressed and frustrated because I didn't know what was going on. I was blaming myself. I thought it was my fault and I was a bad mother. I felt like I was letting her down. I was trying to figure out what to do. The behaviour problem came at school. They never suggested anything and it was depressing not knowing what to do... but it was getting me down and it was the stress levels. I was growling her and yelling. I was pushing her away because I didn't know how to deal with it. It made us grow apart. I did not want to be around her. I didn't want to deal with it. I didn't know how to deal with it. It really stresses me. Other people [people in the family] scatter coz I am going off my head yelling at her (Mother of child with conductive hearing loss - Howard \& Hampton, 2006, p3).
\end{abstract}

In homes, just as in schools, antisocial behavior associated with conductive hearing loss can be mediated by background noise. Disputes and arguments involving people with hearing loss typically arise in noisy social gatherings, especially when alcohol is involved. Sometimes other family members experience frustration and anger because of their family member's hearing related communication difficulties. The following short case studies describe how this can happen and how dire the consequences can be for a family.

One woman with hearing loss accused her husband of 'mumbling'when she could not understand him at a time when there was lots of noise at home because of many visitors staying. She got angry with him and threw something at him, he responded by hitting her, which led to his arrest and jail (Howard, 2007b, p1).

A young husband with hearing loss described how the birth of a new baby made it harder for him to hear. Communication demands on him were greater because his wife wanted more support from him to look after their new baby, but she got angry when he had trouble understanding her above the baby's crying.
On one occasion he had to go to hospital after she became angry and hit him. She had asked him to get something from the shop but he had misunderstood what she said and bought the wrong thing with the last of their money (Howard, 2007b, p1).

There is also some evidence, from studies of nonAboriginal children, that conductive hearing loss can influence family life in other important ways. Children with conductive hearing loss may instigate familial interactions less often than children who can hear well, and may also be less responsive to their parents (Roberts, Burchinal \& Clarke-Klein, 1995). This results in a diminished quantity and quality of social interaction between affected children and caregivers (Hoff-Ginsberg, 1990; Vibbert \& Bornstein, 1989). Mothers with a child who had experienced chronic middle ear disease were more likely to be depressed and to feel that they were less adequate as parents than other mothers (Forgays, Hasazi \& Wasserman, 1992). Some non-Aboriginal Australian mothers also reported that they found it more difficult to feel close to a child with conductive hearing loss (Dorothy Moore, personal communication, 1992).

Other studies among non-Aboriginal children have been less supportive of the long-term effects of early conductive hearing loss (Bowd, 2005). However, it should be remembered that these studies were carried out in non-Aboriginal communities where less severe middle ear disease affects far fewer children, and fewer adults have permanent hearing problems. These nonAboriginal communities also face far fewer other types of social disadvantage than is often the case in Aboriginal communities, and they do not face the challenges involved in being a cultural minority. As a result, the adverse consequences of conductive hearing loss are likely to be more muted than they are in Aboriginal communities (Nienhuys, 1992; Howard, 2006b). This means research outcomes involving non-Aboriginal groups should not be used as a basis for policy and practices applied in Aboriginal communities.

\section{The Implications for Welfare Agencies}

There has been no formal research into hearing loss among Aboriginal welfare clients. This is despite there being both disproportionate numbers of Aboriginal people who have hearing loss (Bowd, 2005, Couzos, Metcalf, $\&$ Murray, 2001) as well as an over representation of Aboriginal people involved with welfare services (Wien et al, 2007, Trewin \& Madden, 2005). There are also clear links between hearing loss and issues associated with involvement with welfare services. We have seen earlier how widespread hearing loss can influence Aboriginal family life (Howard \& Hampton, 2006). There are also 
indications that Australian Aboriginal children with a history of ear disease are more likely to be involved in substance abuse (Lowell, 1994). We know too that non Aboriginal children with hearing loss are more likely to experience sexual abuse than non Aboriginal children (Sullivan, Brookhouser, \& Scanlan, 2000).

Informed speculation would suggest that many, if not most, of Aboriginal welfare clients in Australia, Canada and New Zealand have some degree of hearing loss as a consequence of endemic childhood ear disease. As outlined earlier most of the Australian Aboriginal children who have behaviour problems at school have hearing loss, as do the majority Aboriginal adults who become prison inmates in Australia. Many of these children and adults will be involved with welfare agencies at some point.

Widespread Aboriginal hearing loss has a number of practical implications for welfare agencies. These include the importance of determining if Aboriginal clients have hearing loss, plus ensuring caseworkers and, as much as is possible, family, carers and educators know and use effective communication strategies with welfare clients who have hearing loss. These clients also need to have access to health services to treat any active ear disease or have surgery to repair damage to ear drums, if this is needed. Further, formal research of this significant issue among Aboriginal welfare clients is urgently needed

These matters are not easily addressed as the information and/or infrastructure needed to do so is mostly not readily available. For example, Aboriginal children on reserves in Canada and in remote communities in Australia have the worst ear health in their respective nations, as well as very limited access to health services. A Canadian reviewer of this article pointed out that many children living on reserves can only access adequate ear health services when they are taken into care (Shangreaux and Blackstock, 2004). Nevertheless, the awareness that conductive hearing loss has important communication and social outcomes for many Aboriginal people who are involved with welfare agencies is an important first step on what will be a long journey.

\section{Discussion}

Drawing on research carried out in Australia, this article has outlined the significance of conductive hearing loss in both intercultural and also potentially in same-culture communication. Attempts to address the health aspects of middle ear disease in Australia over the last thirty years have had limited success (Bowd, 2005; Morris et al., 2007). In isolation, however, and without consideration of the social and educational consequences of conductive hearing loss for Aboriginal children and adults, such health initiatives are likely to have a limited effect on the cycle of poverty and the way it can unfold for Aboriginal people affected by conductive hearing loss and its consequences; poverty contributes to a higher incidence of middle ear disease among children, which results in conductive hearing loss, which leads on to poor social, educational and employment outcomes, which perpetuate poverty.

Middle ear disease is an important health issue, but there is also a need for a greater focus on the communicative and social consequences of Aboriginal hearing loss. It is a problem whose impact is seldom fully appreciated or addressed.

Widespread Aboriginal hearing loss acts as a direct barrier to communication. It also contributes indirectly to the linguistic and cultural barriers that constrain intercultural communication. These barriers can have a negative impact on social and emotional wellbeing, educational opportunity and access to almost all services where access depends on effective communication. Many of the problems that arise are not caused solely as a result of conductive hearing loss. They arise because communication is impeded by the interaction of noisy environments and culturally unfamiliar communication processes with widespread hearing loss. From what we presently know, to successfully overcome these barriers, three things are important; knowing which people do have conductive hearing loss, improving environmental acoustics by limiting background noise levels, and adopting more effective communication processes, including culturally based communication strategies.

\section{What does this mean in practical terms?}

1. Access to audiological services for hearing tests is often problematic, especially in remote areas, but 'easy-to-use' hearing screening strategies can help to identify probable hearing loss (Howard, 1993).

2. There are a number of ways to acoustically improve an environment. In schools sound field amplification where the teachers voice is amplified to the whole class is beneficial as is adapting buildings to prevent noise intrusion and limit reverberation (echo) in rooms (Wilson et al., 2002). One inexpensive intervention is simply to minimize background noise levels during communication. All too often, nonAboriginal professionals with good hearing decide whether or not an acoustic environment is adequate for communication with Aboriginal people who have conductive hearing loss that the professional does not know or think about. Communication outcomes can be significantly improved if people are aware that they may be talking with people who quite possibly have conductive hearing loss, and if they take steps to 


\section{First Peoples Child \& Family Review, Volume 3, Number 4, 2007}

minimise background noise levels (Howard, 2006a).

3. Communication problems that arise because of unfamiliar cultural communication strategies and differing 'world views' can be addressed through the involvement of Aboriginal staff in service provision and as communication brokers, as well as training all staff $^{2}$ in effective communication strategies for people with hearing loss (Howard, 2007a). These strategies include using visual cues during verbal explanations, selectively using amplification devices, spending more time on 'communication' and being careful not to make inappropriate judgments about capacity or motivation on the basis of people's communication difficulties (see www.eartroubles.com for more information).

This is not to suggest that we already know enough about these issues to be certain about how best to address them. There is a need for more research into the consequences of widespread conductive hearing loss among Aboriginal people - children and adults, and ways of addressing this problem. In the field of education, there have been a few in depth studies. In the criminal justice and the welfare sectors, as well as in other contexts, there is much more work to be done. Without a fuller understanding of the long term and 'life cycle' consequences of conductive hearing loss, in interaction with other environmental and cultural factors, it will be difficult to fully assess and effectively address the problems arising from childhood middle ear disease. Nevertheless, the results of the work in Australia do point to steps that can be taken now to minimize some of the consequences of conductive hearing loss for individuals, their families and their communities.

There is a parallel in the disadvantage faced by the Aboriginal peoples of Canada, Australia, New Zealand, because of the role that conductive hearing loss plays in the perpetuation of the cycle of poverty that affects Aboriginal minorities in first world nations. Further, it has been estimated that a third of the populations in developing countries experience hearing loss because of childhood ear disease that is related to poverty (Berman, 1995). This means there are at least a billion people world wide who can be assisted by a better understanding of these issues.

\section{Endnotes}

1. Classes of Aboriginal students taught by a non-Aboriginal teacher who speaks standard Australian English.

2. While Aboriginal people can often communicate effectively with Aboriginal people with hearing loss, they are often unaware of their own or others' hearing loss. When they become aware of these issues they can use their communication skills even more effectively.

\section{References}

Berman, S. (1995). Otitis Media in Developing Countries. Pediatrics, 96(1), 126-131.

Bluestone, C. D. (1998). Epidemiology and pathogenesis of chronic suppurative otitis media: Implications for prevention and treatment. International Journal of Pediatric Otorhinolaryngology, 42(3), 207-223.

Bowd, A. D. (2005). Otitis media: Health and social consequences for Aboriginal youth in Canada's north. International Journal of Circumpolar Health, 64(1), 5-15.

Bowers, M. (1986). Hearing Impairment in Prisoners. Auckland, NZ: Deafness Research Foundation.

Couzos, S., Metcalf, S., \& Murray, R. (2001). Systematic review of existing evidence and primary care guidelines on the management of otitis media in Aboriginal and Torres Strait Islander populations. Canberra, ACT: Health Media Unit, Commonwealth Department of Health and Aged Care.

Erickson, F. \& Mohatt, G. (1981). Cultural differences in teaching styles in Odawa schools: A sociolinguistic approach. In H. T. Trueba, G. P. Guthrie and H. H. Au (Eds), Culture and the bilingual classroom: Studies in classroom ethnography (pp. 105-119). Rowley, MA: Newbury House.

Finitzo-Hieber, T. \& Tillman, T. (1978). Room acoustics effects on monosyllabic word discrimination ability for normal and hearing-impaired children. Journal of Speech and Hearing Research, 21, 440-458.

Forgays, D., Hasazi, J., \& Wasserman, R. (1992). Recurrent otitis media and parenting stress in mothers of two-yearold children. Journal of Developmental and Behavioral Pediatrics, 13, 321-325

Greville, K. A. (2001). Hearing impaired and deaf people in New Zealand: Population numbers and characteristics. Auckland, NZ: Greville Consulting. Available online: http://www.grevilleconsulting.co.nz/Hearing\%20impaired $\%$ 20and $\% 20$ deaf $\% 20$ people $\% 20 \mathrm{in} \% 20 \mathrm{New} \% 20$ Zealand.doc.

Harris, S. (1980). Culture and learning: Tradition and education in northeast Arnhemland. Darwin, NT: Department of Education.

Hoff-Ginsberg, E. (1990). Maternal speech and the child's development of syntax: A further look. Journal of Child Language, 17, 85-99.

Hogan, S. \& Moore, D. (2003). Impaired binaural hearing in children produced by a threshold level of middle ear disease, Journal of the Association for Research in Otolaryngology, 4, 123-129.

Hookey, T. (2007). A framework for Action. Paper presented at the Hear Speak Live Conference. Brisbane, QLD.

Howard, D. (1993). Knowing who may have a hearing loss. The Aboriginal Child at School, 21(1), 27-33. Available online: http://www.eartroubles.com/attachments/Knowing\%20who \%20may $\% 20$ have $\% 20 \mathrm{a} \% 20$ hearing $\% 20$ loss.pdf.

Howard, D. (1994). Culturally responsive classrooms: a way to assist Aboriginal students with hearing loss in urban 
schools. In S. Harris and M. Malin (Eds), Aboriginal Kids in Urban Classrooms (pp. 37-50). Wentworth Falls, NSW: Social Science Press.

Howard, D. (2004). Why we need more Aboriginal adults working with Aboriginal students. The Australian Journal of Teacher Education, 29(1), 14-22. Available online: http://ajte.education.ecu.edu.au/ISSUES/PDF/291/Howard. pdf

Howard, D. (2006a). Conductive hearing loss and behaviour problems amongst urban Indigenous students. Unpublished PhD thesis. Darwin, NT: Charles Darwin University.

Howard, D. (2006b). Mixed messages: Cross-cultural management in Aboriginal community controlled health services. Darwin, NT: Phoenix Consulting. Available online: http://www.healthinfonet.ecu.edu.au/html/html_community/ ear_health_community/mixed_messages.pdf.

Howard, D. (2006c). Communication, listening and criminal justice. Magistrates' conference. Darwin, NT. Available online: http://www.healthinfonet.ecu.edu.au/html/html_community/ ear_health_community/com_listening_crim_justice.pdf.

Howard, D. (2007a). Group Training Northern Territory Indigenous Hearing and Mentoring Strategy Project. Final report to the Commonwealth Department of Education, Science and Training. Darwin, NT: Phoenix Consulting.

Howard, D. (2007b). Indigenous Housing, Hearing Loss and Social Problems. Available online: http://www.eartroubles. com/attachments/Indigenous\%20Housing $\% 20$ Hearing\%20 Loss\%20and\%20Social\%20Problems2.pdf.

Howard, D. \& Hampton, D. (2006). Ear disease and Aboriginal families. Aboriginal and Islander Health Worker Journal, 30(4), 9-16. Available online: http://www.healthinfonet.ecu. edu.au/html $/ \mathrm{html}$ community/ear health community/aihwj_howard.pdf.

Howard, D., Quinn, S., Blokland, J., \& Flynn, M. (1991). Aborigi nal hearing loss and the criminal justice system. Aboriginal Law Bulletin, 3(65), 9-11. Available online: http://www.austlii. edu.au/au/journals/AboriginalLB/1993/58.html.

Jacobs, A. (1988). A descriptive study of the bilingual language development of Aboriginal children in the eastern goldfields region of Western Australia. Unpublished report.

Lay, K. (1990). Hearing loss in an adult Aboriginal population. Unpublished thesis. Brisbane, QLD: University of Queensland.

Lowell, A. (1994). Communication and learning in an Aboriginal school: the influence of conductive hearing loss. Unpublished PhD thesis. Sydney, NSW: University of Sydney.

Lowell, A., Marrnganyin, B., Brown, I., Snelling, P., Flack, M., Christie, M. et al. (2004). Sharing the true stories: improving communication in Indigenous health care. Cooperative Research Centre for Aboriginal and Tropical Health (CRCATH) Project Report. Darwin, NT. Available online: http://www.sharingtruestories.com.

Malin, M. (1990). Why is life so hard for Aboriginal students in urban classrooms? Aboriginal Child at School, 18(1), 9-29.
Massie, R. (1999). The effects of sound field classroom amplification on the communicative interactions of Aboriginal and Torres Strait Islander children. Unpublished PhD thesis. Brisbane, QLD: University of Queensland.

Morris, P.S., Leach, A.J., Halpin, S., Mellon, G., Gadil, G., Wigger, C., Mackenzie, G., Wilson, C., Gadil, E. \& Torzillo, P. (2007). An overview of acute otitis media in Australian Aboriginal children living in remote communities. Vaccine, 24(13), 2389-2393.

Murray, N. \& La Page, E. (2004). Hearing health of New South Wales prison inmates. Australian and New Zealand Journal of Public Health, 28, 537-541.

National Aboriginal Community Controlled Health Organisation. (NACCHO) (2003). Ear Trial and School Attendance Project.

Nienhuys, T.G. (1992). The significance of prelingual conductive hearing loss for auditory and linguistic development of Aboriginal infants. Conference Proceedings Medical Options for Prevention and Treatment of Otitis Media in Australian Aboriginal Infants, Menzies School of Health Research and the Australian Doctors Fund Darwin, 16-18 February. Available online: http://www.adf.com.au/archive. php?doc id $=137$.

Roberts, J. E., Burchinal, M. R., \& Clarke-Klein, S. M. (1995). Otitis media in early childhood and cognitive, academic, and behaviour outcomes at 12 years of age. Journal of Pediatric Psychology, 20, 645-660.

Shangreaux, C. \& Blackstock, C. (2004). Staying at Home: Examining the Implications of Least Disruptive Measures in First Nations Child and Family Service Agencies. Ottawa: First Nations Child \& Family Caring Society of Canada. Accessed from http://www.fncfcs.com/docs/Staying at Home.pdf.

Sullivan, P., Brookhouser, P., \& Scanlan, M. (2000). Maltreatment of deaf and hard of hearing people. In Hindley, P. and Kitson, N. (Eds.), Mental Health and Deafness (pp. 149-184). London: Whurr Publishers.

Trewin, D. \& Madden, R. (2005). The Health and Welfare of Australia's Aboriginal and Torres Strait Islander Peoples. A report jointly sponsored by the Australian Bureau of Statistics and Australian Institute of Health and Welfare. Canberra: Commonwealth of Australia. Available online: http://www.aihw.gov.au/publications/ihw/hwaatsip05/ hwaatsip05.pdf.

Vibbert, M. \& Bornstein, M. H. (1989). Specific associations between domains of mother-child interaction and toddler language and pretence play. Infant Behavior and Development, 12, 163-184.

Whitlock, J. \& Dodd, G. (2003). Classroom Acoustics Milestone 6 Report: An investigation of the classroom acoustic needs of primary school children. Auckland, NZ: Auckland Uniservices. Available online: http://www.minedu.govt. nz/web/downloadable/d19945 v1/classroom-acoustics--milestone-6-report-feb04-ema.doc.

Wien, F., Blackstock, C., Loxley, J., \& Trocmè, N. (2007). 


\section{First Peoples Child \& Family Review, Volume 3, Number 4, 2007}

Keeping First Nations children at home: A few Federal policy changes could make a big difference. First Peoples Child and Family Review, 3(1), 10-14. Available online: http://www.fncaringsociety.ca/pubs/vol3num1/Wien_Blackstock_Loxley_Trocme_pp10.pdf.

Wilson, O., Valentine, J., Halstead, M., McGunnigle, K., Dodd, G., Hellier, A., et al. (2002). Classroom acoustics: a New Zealand perspective. Wellington, NZ: Oticon Foundation. Available online: http://www.oticon.org.nz/pdf/ClassroomAcousticsReportprintedversion.pdf.

World Health Organisation (WHO). (1996). Prevention of hearing impairment from chronic otitis media. Report of a WHO/CIBA Foundation workshop, London, 19-21 November 1996. Available online: http://www.who.int/pbd/deafness/en/chronic_otitis media.pdf.

Yonovitz, L. \& Yonovitz, A. (2000). PA-EFL: A phonological awareness program for indigenous EFL students with hearing disabilities. Teaching English as a Second or Foreign Language, 4(4). Available online: http://www.kyoto-su.ac. jp/information/tesl-ej/ej16/cfl.html.

Zubrick, S., Lawrence, D., Silburn, S., Blair, E., Milroy, H. \& Wilkes, T. (2004). The Western Australian Aboriginal child health survey: the health of Aboriginal children and young people. Perth, WA: Telethon Institute for Child Health Research. Available online: http://www.ichr.uwa.edu. au/waachs/publications/volume_one.lasso. 